\title{
Hepatocellular carcinoma with colonic metastasis
}

\author{
Tzu-Ming $\underline{\mathrm{Ou}}^{1,3}, \mathrm{MD}$, Wen-Chiuan $\underline{\mathrm{Tsai}}{ }^{2}$, MD, Tsai-Yuan $\underline{\mathrm{Hsieh}}^{1}$, MD, PhD, Yu-Lueng $\underline{\operatorname{Shih}}{ }^{1}$, MD, PhD
}

ABSTRACT Hepatocellular carcinoma with colonic metastasis is rare. It mainly occurs by direct invasion and presents with bloody stools. We describe a patient with haematogenous metastasis to the rectum who presented with tenesmus. To our knowledge, such an association has not been reported previously. Colonic metastasis should be considered when patients with hepatocellular carcinoma present with bloody stools or tenesmus.

Keywords: colonic metastasis, hepatocellular carcinoma

\section{INTRODUCTION}

Hepatocellular carcinoma (HCC) is one of the most common malignant tumours in the world. More than 500,000 people are diagnosed with HCC each year, and the disease is responsible for 250,000 deaths annually. ${ }^{(1)}$ Extrahepatic metastasis to the colon is rare and usually presents with bloody stools. In this study, we report the case of a patient with HCC who was previously known to have metastases to the adrenal gland and brain. He presented with tenesmus and was found to have two synchronous polyps in the ascending colon, near the caecum and rectum, on colonoscopy. To our knowledge, this is the first report of such an association between extrahepatic metastasis of HCC to the colon and tenesmus.

\section{CASE REPORT}

A 62-year-old man with a history of chronic hepatitis B since childhood was diagnosed with HCC (stage I cT1NOM0) in April 2009 while undergoing left lateral lobectomy. During the following several months, recurrence was observed at segments 6 and 7 , and the patient received radiofrequency ablation (RFA), percutaneous ethanol injection (PEI) and CyberKnife stereotactic radiosurgery. In October 2010, bilateral adrenal metastasis was noted, and transarterial chemoembolisation (TACE), thalidomide therapy and CyberKnife stereotactic radiosurgery were performed. However, direct invasion of the inferior vena cava by the right adrenal metastasis was observed in June 2011. In February 2012, cerebellum metastasis was detected, and the patient underwent CyberKnife stereotactic radiosurgery again. In June 2012, he visited our outpatient clinic reporting tenesmus lasting for several days. A colonoscopy revealed a single polyp, $0.3 \mathrm{~cm}$ in size, at the ascending colon near the caecum, and another polyp, $1.0 \mathrm{~cm}$ in size, at the rectum (Fig. 1). Polypectomy was performed for both sites and histopathological evaluation confirmed metastatic HCC (Fig. 2). However, the patient died due to aspiration pneumonia in July 2012 while further treatment was being planned.

\section{DISCUSSION}

The prevalence of extrahepatic metastasis in HCC patients has been reported to range between $13.5 \%$ and $42 \%$ in a

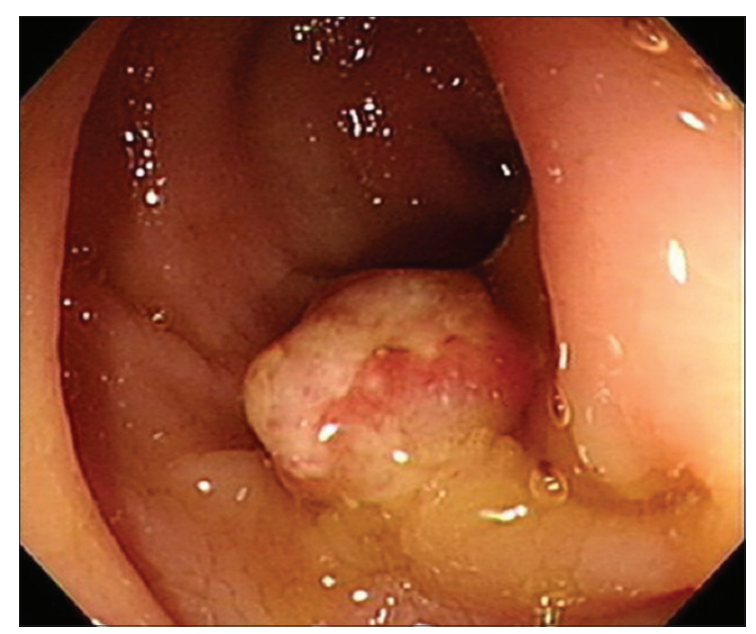

Fig. 1 Colonoscopic image shows an adenoma polyp, $1.0 \mathrm{~cm}$ in size, over the rectum.

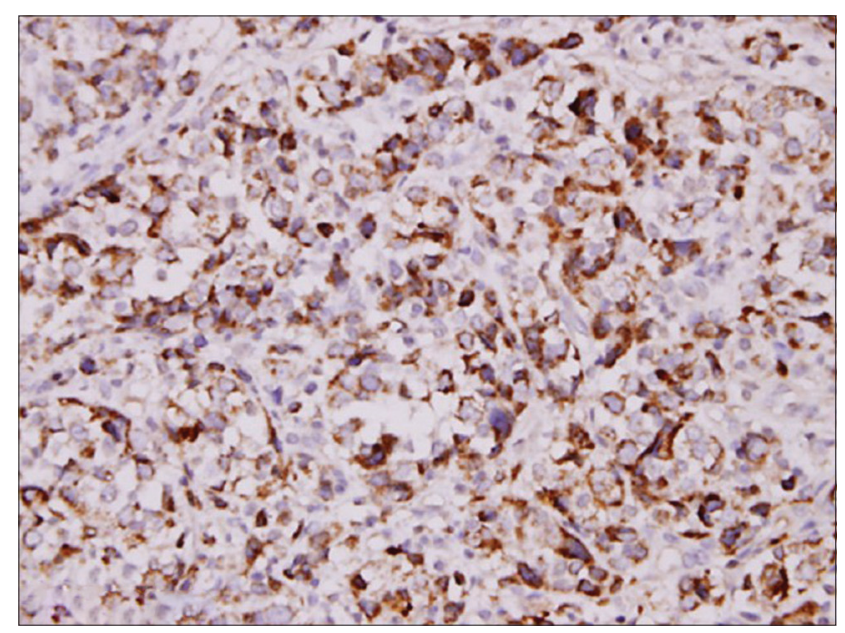

Fig. 2 Photomicrograph shows tumour cells positive for arginase (Arginase, $\times 400$ ).

previous study. ${ }^{(2)}$ According to the literature, ${ }^{(2-5)}$ the most common site of extrahepatic metastasis is the lung, followed by lymph nodes, ${ }^{(2-5)}$ bone $^{(2-5)}$ and adrenal gland..$^{(2-5)}$ There are three known routes of extrahepatic metastasis from HCC: haematogenous (56\%), lymphogenous $(26.7 \%)$ and direct invasion $(21.8 \%){ }^{(4)}$

${ }^{1}$ Department of Internal Medicine, ${ }^{2}$ Deaprtment of Pathology, Tri-Service General Hospital, National Defense Medical Center, Taipei, ${ }^{3}$ Department of Internal Medicine, Kaohsiung Armed Forces General Hospital, Kaohsiung, Taiwan

Correspondence: DrYu-Lueng Shih, Assistant Professor, Division of Gastroenterology, Tri-Service General Hospital, No. 325, Sec 2, Cheng-Gong Rd, Neihu, Taipei 114, Taiwan. albreb@ms28.hinet.net 
Table I. Summary of patients with colonic metastasis from hepatocellular carcinoma reported in the literature.

\begin{tabular}{|c|c|c|c|c|c|c|c|c|c|}
\hline Study (year) & Symptom & $\begin{array}{l}\text { Colonic } \\
\text { site }\end{array}$ & Cirrhosis & Aetiology & $\begin{array}{c}\text { Previous } \\
\text { TAE or TACE }\end{array}$ & Surgery & $\begin{array}{c}\text { Survival } \\
\text { period } \\
\text { (mths) }\end{array}$ & $\begin{array}{l}\text { Presumed } \\
\text { mode of } \\
\text { metastasis }\end{array}$ & $\begin{array}{l}\text { Interval* } \\
\text { (mths) }\end{array}$ \\
\hline $\begin{array}{l}\text { Hashimoto et al(16) } \\
(1996)\end{array}$ & Melaena & Transverse & + & $\mathrm{HCV}$ & + & + & $>4$ & Direct invasion & 63 \\
\hline $\begin{array}{l}\text { Cosenza et } \mathrm{al}^{(15)} \\
(1999)\end{array}$ & Bloody stool & Ascending & + & $\mathrm{HCV}$ & - & + & $>25$ & Haematogenous & 47 \\
\hline \multirow{2}{*}{$\begin{array}{l}\text { Lin et } \mathrm{al}^{(7)} \\
(2000)\end{array}$} & $\begin{array}{l}\text { Epigastric pain } \\
\text { and stool occult } \\
\text { blood positive }\end{array}$ & NA & + & HBV & - & NA & 1.2 & Direct invasion & Simultaneous \\
\hline & Bloody stool & NA & + & NA & - & NA & 4 & Direct invasion & Simultaneous \\
\hline $\begin{array}{l}\text { Tapuria et } \mathrm{al}^{(9)} \\
(2007)\end{array}$ & Melaena & Ascending & + & Autoimmune & - & + & $>1$ & Haematogenous & NA \\
\hline $\begin{array}{l}\text { Hirashita et al }{ }^{(11)} \\
(2008)\end{array}$ & Melaena & Ascending & + & $\mathrm{HCV}$ & + & + & 1 & Direct invasion & 31 \\
\hline $\begin{array}{l}\text { Ng et } \mathrm{al}^{(13)} \\
(2007)\end{array}$ & Bloody stool & Ascending & + & HBV & - & + & $>60$ & Haematogenous & 6 \\
\hline $\begin{array}{l}\text { Nozaki et al }{ }^{(14)} \\
(2008)\end{array}$ & Bloody stool & Ascending & NA & NA & - & - & $<1$ & NA & 24 \\
\hline $\begin{array}{l}\text { Present study } \\
\text { (2013) }\end{array}$ & Tenesmus & $\begin{array}{l}\text { Ascending } \\
\text { and rectum }\end{array}$ & - & HBV & + & - & 1 & Haematogenous & 38 \\
\hline
\end{tabular}

*Time interval between the diagnosis of hepatocellular carcinoma and the diagnosis of colonic metastasis.

-: negative; +: positive; HBV: hepatitis B virus; HCV: hepatitis C virus; NA: not available; TACE: transarterial chemoembolisation; TAE: transarterial embolisation

Metastasis to the gastrointestinal (GI) tract is rare. Its reported incidence among clinical patients with HCC ranges from $0.5 \%$ to $4.4 \%$, ${ }^{(4,6)}$ while that among autopsy cases is $4 \%{ }^{(4,7,8)}$ The most often affected sites of metastasis in the Gl tract are the duodenum and stomach. ${ }^{(7,8)}$ Invasion of the colon is rare. ${ }^{(7)}$ Metastasis to the Gl tract mainly occurs by direct invasion $^{(7,8)}$ and less commonly by the haematogenous route. ${ }^{(7,8)}$

Vascular invasion such as portal vein thrombosis may be a key point of haematogenous spread. ${ }^{(9)}$ The presence of tumour thrombosis in the portal vein may cause a reversal of flow, which possibly serves as the mechanism of haematogenous metastasis of HCC to the Gl tract. ${ }^{(9)}$ Transarterial embolisation (TAE) and TACE may also induce elevation of portal venous pressure and backward flow of tumour emboli, ${ }^{(10)}$ and as a result, HCC may invade the adjacent organs, such as the colon, or other parts of the GI tract. Haematogenous metastasis is not related to elevated alpha-fetoprotein, but may be associated with vascular invasion such as portal vein or inferior vena cava invasion. . $^{(-9)}$

Bloody stool is the most frequent symptom of colonic metastasis. (11) The treatment of HCC depends on the tumour stage. Primary HCC or intrahepatic metastasis can be treated using curative resection, RFA, PEI, TAE and TACE. In spite of the improvements in medical treatment, most HCC patients are diagnosed at advanced stages, and therefore, it becomes impossible to conduct curative resection due to poor prognosis. When intrahepatic lesions are well controlled and in good hepatic reserve, symptomatic or life-threatening metastasis should be treated. ${ }^{(2,3)}$ RFA is technically difficult because of its high risk of perforation, ${ }^{(11)}$ and TAE and TACE are not effective in treating HCC with Gl tract metastasis. ${ }^{(11)}$ Surgical resection may be the most effective treatment option for GI tract metastasis of HCC.

According to Fujii et al, the median survival time of patients with GI tract invasion treated using surgical resection is longer than those who receive nonsurgical and supportive treatment. ${ }^{(12)}$ The median survival time of patients following the diagnosis of extrahepatic metastasis was reported to be 4.9-8.1 months. ${ }^{(2,3,5)}$ Hirashita et al, in a recent case series, reported that the median survival of HCC patients with colonic metastasis was only 2.5 months. ${ }^{(11)}$ Predictors for poor prognosis included performance status and intrahepatic lesion controllability. ${ }^{(3,5)}$ Patients with extrahepatic metastases generally have more advanced intrahepatic tumours or vessel invasion when first diagnosed with HCC. ${ }^{(4)}$ Studies suggest that mortality in patients with extrahepatic metastasis is not directly associated with the metastasis itself; ${ }^{(2,3)}$ its major cause may be related to the progression of the intrahepatic lesion.

A search of the MEDLINE database for the English language literature showed that in recent years, ten patients had been reported to have colonic metastasis from HCC (Table I). ${ }^{(7,9-11,13-16)}$ A major symptom was bloody stool. The most frequent sites of metastasis were the ascending and transverse colons, suggesting that most HCC colonic metastases would directly invade the adjacent colon. Our patient was presumed to have haematogenous metastasis, probably via inferior vena cava invasion, as the metastatic sites were far from the liver. Six patients had direct invasion and four patients, including our patient, were reported to have haematogenous spread. For one patient, the mode of metastasis was not known. Except for our patient, 
the other patients with haematogenous metastasis had cirrhosis, indicating that portal hypertension may be a risk factor for the haematogenous metastasis of HCC to the colon or other parts of the Gl tract. Most patients who underwent TAE or TACE showed evidence of metastasis by direct invasion. Among reported patients, those who underwent surgery for colonic metastatic lesions had longer survival times.

In conclusion, HCC with extrahepatic metastasis at an advanced stage is common, but colonic metastasis is rare and is mainly caused via direct invasion. Haematogenous metastasis of $\mathrm{HCC}$ to the Gl tract may be related to vascular invasion or portal hypertension, and these patients mostly present with bloody stools. To our knowledge, this is the first report of a patient with colonic metastasis of $\mathrm{HCC}$ to the rectum presenting with tenesmus. Colonic metastasis should therefore be considered for patients with hepatocellular carcinoma who present with bloody stools or tenesmus.

\section{REFERENCES}

1. Ramsey WH, Wu GY. Hepatocellular carcinoma: update on diagnosis and treatment. Dig Dis 1995; 13:81-91.

2. Uka K, Aikata H, Takaki S, et al. Clinical features and prognosis of patients with extrahepatic metastases from hepatocellular carcinoma. World J Gastroenterol 2007; 13:414-20.

3. Uchino K, Tateishi R, Shiina S, et al. Hepatocellular carcinoma with extrahepatic metastasis: clinical features and prognostic factors. Cancer $2011 ; 117: 4475-83$.

4. Nakashima T, Okuda K, Kojiro M, et al. Pathology of hepatocellular carcinoma in Japan 232 consecutive cases autopsied in ten years. Cancer $1983 ; 51: 863-77$.
5. Natsuizaka M, Omura T, Akaike T, et al. Clinical features of hepatocellular carcinoma with extrahepatic metastases. J Gastroenterol Hepatol 2005; 20:1781-7.

6. Tsubouchi E, Hirasaki S, Kataoka J, et al. Unusual metastasis of hepatocellular carcinoma to the esophagus. Intern Med 2005; 44:444-7.

7. Lin CP, Cheng JS, Lai KH, et al. Gastrointestinal metastasis in hepatocellular carcinoma: radiological and endoscopic studies of 11 cases. J Gastroenterol Hepatol 2000; 15:536-41.

8. Chen LT, Chen CY, Jan CM, et al. Gastrointestinal tract involvement in hepatocellular carcinoma: clinical, radiological and endoscopic studies. Endoscopy 1990; 22:118-23.

9. Tapuria N, Sinha CK, Michael NG, Fisher PW. Haematogenous metastasis to ascending colon in a patient with hepatocellular carcinoma and autoimmune hepatitis. Eur J Gastroenterol Hepatol 2007; 19:607-9.

10. Hu ML, Tai WC, Chuah SK, et al. Gastric metastasis of hepatocellular carcinoma via a possible existing retrograde hematogenous pathway. J Gastroenterol Hepatol 2010; 25:408-12.

11. Hirashita T, Ohta M, Iwaki K, et al. Direct invasion to the colon by hepatocellular carcinoma: report of two cases. World J Gastroenterol 2008; 14:4583-5.

12. Fujii K, Nagino M, Kamiya J, et al. Complete resection of hepatocellular carcinoma with direct invasion to the stomach remnant. J Hepatobiliary Pancreat Surg 2004; 11:441-4.

13. Ng DS, Chok KS, Law WL, Collins RJ, Fan ST. Long-term survival after resection of extrahepatic recurrence of hepatocellular carcinoma at the right colon. Int J Colorectal Dis 2007; 22:1411-2.

14. Nozaki Y, Kobayashi N, Shimamura T, et al. Colonic metastasis from hepatocellular carcinoma: manifested by gastrointestinal bleeding. Dig Dis Sci 2008; 53:3265-6.

15. Cosenza CA, Sher LS, Poletti BJ, et al. Metastasis of hepatocellular carcinoma to the right colon manifested by gastrointestinal bleeding. Am Surg 1999; 65:218-21.

16. Hashimoto M, Watanabe G, Matsuda M, et al. Case Report: gastrointestinal bleeding from a hepatocellular carcinoma invading the transverse colon. J Gastroenterol Hepatol 1996; 11:765-7. 